\title{
Studies on Stylonethes sterkii sp. nov. I. Morphology and Systematic Position.
}

\author{
By \\ Laura Garnjobst, \\ Zoological Laboratory, Stanford University, California.
}

With Plates I and II, and 1 Text-figure.

WHILE studying some of the ciliates found in the region of the Marine Biological Laboratory at Plymouth, England, from January to May, 1929, the author collected from Chelson Meadow a hypotrich which undergoes binary fission only during encystment. This interesting behaviour, which appears to be rare among the Hypotrichida, led to a study of the morphology of the free-swimming form; preliminary to further investigations, including a study of both protective and reproductive cysts.

The organism has been named Stylonethes sterkii, reasons for which are presented in this paper.

\section{Acknowledgment.}

This investigation was begun when the author was a Fellow of the Oregon Division of the American Association of University Women, in the year 1928-29. She wishes to extend thanks to Dr. E. J. Allen, F.R.S., Director of the Marine Biological Laboratory of the United Kingdom, Plymouth, England, for the use of a table and for the collecting assistance and equipment put at her disposal during her stay at the laboratory ; to Dr. Harold Kirby, Jr., of the University of California at Berkeley, for criticizing the manuscript ; and to Dr. C. V. Taylor of Stanford University, for his many kindnesses and helpful suggestions. The writer is also indebted to Dr. C. A. Kofoid of the University of California, for the use of his extensive library.

\section{Culture.}

TEChNIQUe.

Both protective and reproductive cysts of $S$. sterkii remain viable when dried. This discovery made possible a transfer of the new hypotrich in May, 1929, from Plymouth to Stanford University, where the strain has been continued to the present time (July, 1933).

The following wheat infusion method of culturing was used exclusively. Twenty grains of wheat were cracked and then boiled in 15 c.c. of glass 
distilled water for from three to five minutes. The fluid containing numerous starch grains was used immediately after cooling and was transferred to the culture by means of a pipette having a bore of $1.5 \mathrm{~mm}$.

Experiments have shown that thriving cultures are most easily maintained when complete evaporation of the medium takes place at intervals. Consequently, the organisms were grown in watchglasses holding conveniently about 4 c.c. of fluid. These were ordinarily enclosed in Petri dishes to prevent evaporation and to facilitate handling, but when mass encystment and complete evaporation of the medium was desired, the cover was removed. Or, the cover may be partly removed so that it protects the watchglass from dust but leaves a wide open gap between the two dishes. Within 8-10 hours, at a temperature varying from $15-22^{\circ} \mathrm{C}$, the cultures were completely dried out.

New cultures were started daily when free-swimming individuals were wanted for study. By means of a mouth pipette twenty organisms from a thriving culture were transferred to a watchglass containing 4 c.c. of tap water and a drop of fresh wheat infusion. A drop of infusion was added daily to old cultures until protective cysts began to appear (2-4 days). Then they were allowed to dry out. Thus it can be arranged that there are always on hand about as many new cultures as old ones, and a reserve supply of dry cysts. If the study of active organisms is to be suspended for a few days or weeks, it is safe to rely upon the stock of dry cysts to begin new cultures, as was proved by the transfer of cysts in watchglasses from England to California. These cysts were about three weeks old when they arrived. Excystment occurred in three to four hours after distilled or tap water had been added.

\section{Methods of Preparation.}

The following description of S. sterkii is based mainly on observations made upon the living organism, although for purposes of confirmation and for study of fine details of structure, permanent mounts were made. The iron-alum-hæmatoxylin method of staining was most frequently used, after killing and fixing in Bouin's or Schaudinn's fluid (without acetic acid), the latter being better for the free-swimming forms, and the former for the cysts. Bresslau's (1921) China blue relief staining method was found to be excellent for a comparative study of external structures.

It is a difficult task to observe this form under the high powers of the microscope in living condition for the two following reasons: Rapid evaporation of the medium bursts the pellicle very easily, and the organisms encyst if evaporation proceeds slowly. However, with patience it is possible to acquire skill in manipulation whereby the living organism may be observed for two hours, or even longer in some cases. The locomotor organelles sooner or later stop beating, and after a quiescent period 
they sometimes function again just before death and disintegration. A minute drop of $10 \%$ alcohol, added to the hanging drop by means of a fine pipette, retards the movement of the organisms within a shorter time, and if evaporation is gradual the protoplasm eventually coagulates without much distortion, so that even after death the structures stand out quite clearly. A $1 \%$ solution of eurythane was also tried with some success.

\section{General Morphology.}

The body form of Stylonethes sterkii (Plate I, Fig. 1) may in general be described as an elongated ellipsoid, with a shallow excavation in the anterior portion of the left side. The ventral surface is slightly concave, the periphery is rounded, and the dorsal surface is broadly arched, the body being thickest centrally.

A thin and elastic pellicle, however, permits considerable modification in form. Especially is this apparent when the animal is gorged with food. The dorsal surface is then highly arched, and the anterior end is smaller than the broadly rounded posterior end. Individuals containing few food vacuoles sometimes are bluntly pointed posteriorly.

The structure of the anterior extremity is extraordinarily complex. Ventrally it terminates in a narrow and inconspicuous projecting lip of uniform width. Dorsally it gives rise to a series of typical membranelles, which extend from the anterior end of the right median ventral row of cirri (described below) to the extreme left side of the body, where they pass ventrally and posteriorly to form the left border of the peristome.

The longest membranelles are found at the most anterior point of the body, and they become shorter gradually away from this point in either direction. The bases of the first twelve or thirteen membranelles, beginning at the right, slope downward on the lip. The turn to the ventral surface is accomplished by the next six or seven membranelles, and posterior to these the bases slope gently downward from the margin of the peristome toward the periphery of the body. The peristomal membranelles gradually come to point ventrally and finally they project toward the midline. The number of membranelles varies. From 25 to 48 have been counted, the number being smaller in small individuals, and larger in large individuals.

Thus far the membranelle region is essentially the same as that described in many other members of the Hypotrichida, such as Holosticha rubra Ehrenberg (Wallengren, 1900) and Euplotes patella Ehrenberg (Taylor, 1929). However, in S. sterkii additional and unique structures are situated between the bases of the membranelles.

In the first place, small elevations, within which are found deeply staining spherules, arise in these narrow spaces (Plate II, Fig. 2). The spherules 
are most conspicuous in the first seven or eight inter-membranellar spaces, beginning at the right, and in size (largest about $\cdot 6 \mu$ ) form a closely graded series so that the tenth or eleventh is barely visible. Beyond this point none can be seen, and if present they must be exceedingly small. Careful focusing from the dorsal surface or a frontal view reveals the fact that the first seven or eight spherules are double. The remainder appear to be single. Considerable variation in respect to number was noted. A small individual may have as few as eight. However, without exception, these spherules are clearly evident in organisms killed in Schaudinn's fluid (without acetic acid) and stained with Heidenhain's hæmatoxylin. This is true even when the preparation is greatly de-stained, thus showing exceedingly strong affinity for the dye. They were seen also in the living state as rounded bodies of greater density than that of the surrounding cytoplasm. The function of these unusual structures is not known.

Interpolated between the right side of each membranelle (except the first) and the left side of the elevation is a small, slender motile structure, which at rest is directed at an angle toward the apposing membranelle; that is, in a direction away from the peristome. Its base is about twothirds the length of the membranelle base and so inserted that both proximal and distal ends of the membranelle base extend beyond it. This observation is most easily made in China blue preparations and in those individuals which have rounded up so that the frontal surface is uppermost. The length of this small organelle measures about 3.5 microns in living condition. As observed in China blue preparations, it was found

\section{EXPLANATION OF PLATES.}

All figures were drawn with the aid of the camera-lucida.

PLATE I.

FIG. 1.-Stylonethes sterkii sp. nov., ventral aspect. Semidiagrammatic drawing of living organism. $\times 800$.

\section{PLATE II.}

FIG. 2.-Anterior extremity, dorsal view, showing position of membranelles, intermembranelles, and spherules within elevations. Semidiagrammatic. Heidenhain's hæmatoxylin stain. $\times 1896$.

Frg. 3.-Right end of membranelle series. Membranelles, inter-membranelles, and cirri of transverse row are fimbriated. Light line between membranelles and cirri indicates lip, which was flattened in preparation. China blue relief stain. $\times 1290$.

FIG. 4.-Dorsal aspect, showing three longitudinal rows of cilia. Living organism. $\times 750$.

FIG. 5.-Note accumulation of granules at anterior end. Dorsal view. Heidenhain's hæmatoxylin stain. $\times 750$.

FIG. 6.-Macronuclei and micronuclei, ventral view. Heidenhain's hæmatoxylin stain. $\times 750$. 


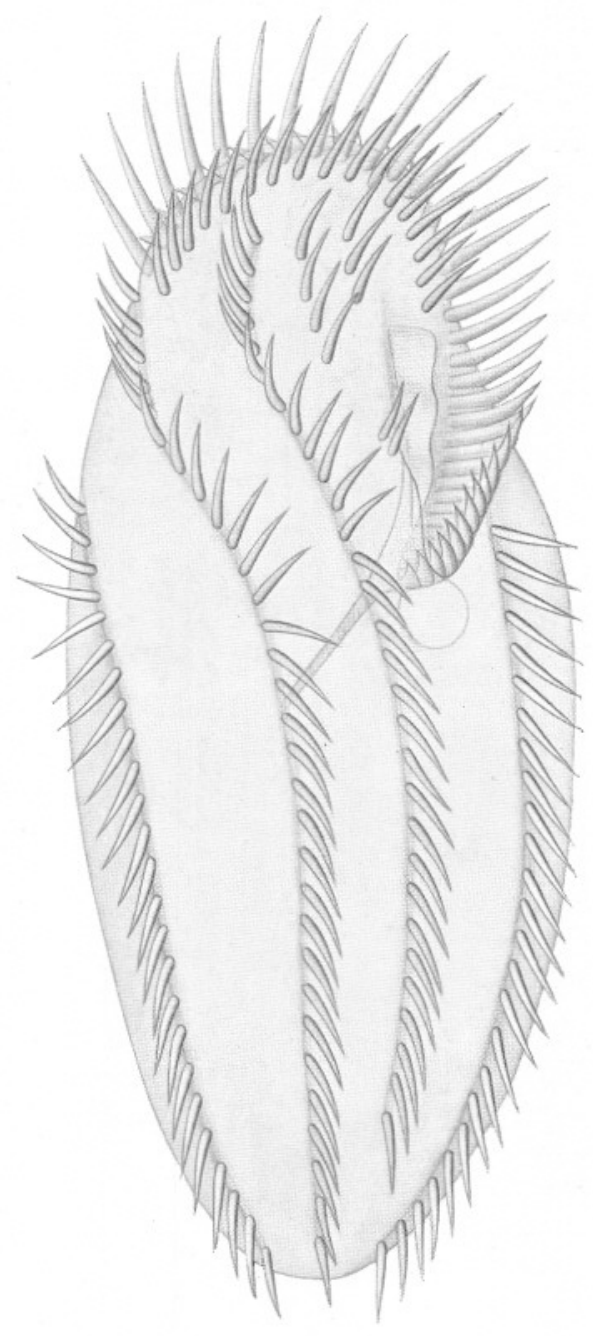




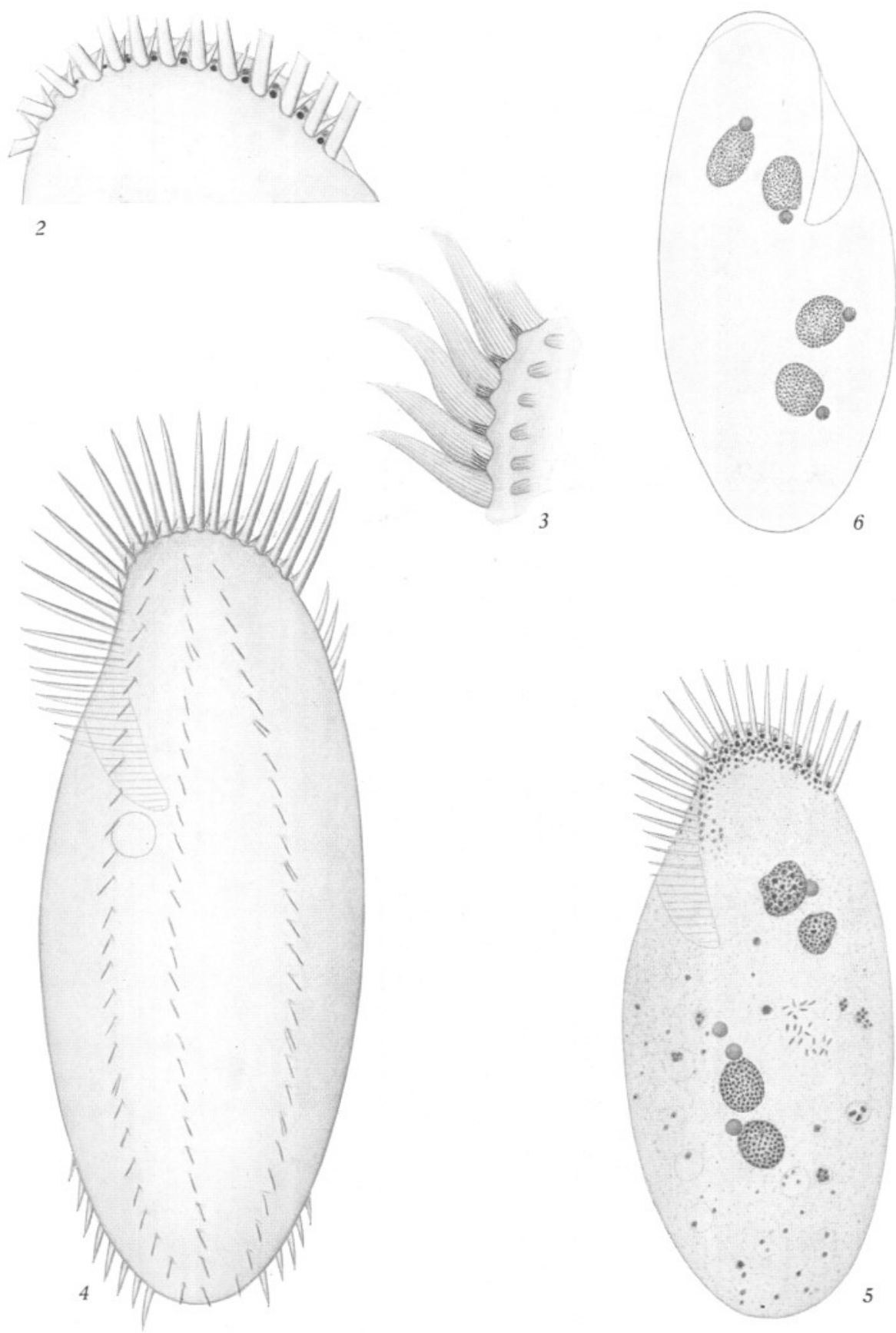

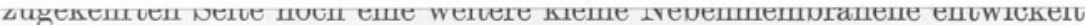
ist. . . . Die Höhe dieser Zwergmembranellen ist gering, aber doch variabel ; einmal habe ich in einem Fall mit der regelrechten eine gleich grosse beobachtet. Der Bau und die Bedeutung dieser Nebenmembranellen ist mir unbekannt. Ihre Bewegung wurde auch nicht beobachtet, nur aus der Querschnittsform erschlossen."

Four longitudinal, uninterrupted rows of closely set cirri constitute the most conspicuous feature of the ventral surface. Two are median in position and two are lateral. The median rows are longer than the laterals, extending across the frontal field with a shallow curve to the right. The 


\section{LIBRARY. M.B.A. \\ PLYMOUTH.}


to be composed of cilia, similar to cirri, membranelles, and undulating membranes, since it shows fimbriation (Plate II, Fig. 3) when cirri and membranelles in the same specimen are thus separated into their component parts.

These minute inter-membranelles were first seen in the living organism and it was thought that their movement might be a passive one caused by the pressure of the two membranelles upon them, first on the one side and then on the other. This is not the case, however, for when observing an organism in a hanging drop preparation just prior to death due to the evaporation of the water, the larger motile organs, such as the membranelles, may cease movement, while these smaller structures continue vigorous movement. It sometimes happens that both stop functioning at the same time, or, the smaller structures may stop first, but occasions such as described above often occurred. Whether or not these organelles are present between all the membranelles is not known. The largest number counted was found in an individual having 38 membranelles. Beginning at the right, fourteen intermembranelles were clearly evident, and if they are present between the remaining membranelles, they must be very small.

While looking through the literature for recently described genera of the Hypotrichida, the writer encountered the article of von Gelei (1929) in which he briefly described "Nebenmembranellen" or "Zwergmembranellen " in Spirofilum tisice n. sp., n. gen. (according to Rossolimo (1929), a new species of the genus Hypotrichidium Ilowaisky, 1921). The position of this organelle, according to von Gelei, seems to be similar to that just described for $S$. sterkii, i.e. between the membranelles, but whether or not the structure is the same cannot be determined from the information given. Ilowaisky (Rossolimo, 1929) studied only the living specimens of his new form, $H$. conicum, and did not mention having seen minute organelles between the membranelles. Von Gelei's description (1929, p. 175) is as follows :-

"Mir ist an diesen Membranellen eine merkwürdige Erscheinung aufgefallen, die nämlich, dass neben beiden Organen an ihrer einander zugekehrten Seite noch eine weitere kleine Nebenmembranelle entwickelt ist. . . Die Höhe dieser Zwergmembranellen ist gering, aber doch variabel ; einmal habe ich in einem Fall mit der regelrechten eine gleich grosse beobachtet. Der Bau und die Bedeutung dieser Nebenmembranellen ist mir unbekannt. Ihre Bewegung wurde auch nicht beobachtet, nur aus der Querschnittsform erschlossen."

Four longitudinal, uninterrupted rows of closely set cirri constitute the most conspicuous feature of the ventral surface. Two are median in position and two are lateral. The median rows are longer than the laterals, extending across the frontal field with a shallow curve to the right. The 
right lateral row originates at the periphery about one-third of the way back from the anterior end, and from this point posteriorly it becomes set in from the margin, as shown in Plate I, Figure 1. The anterior origin of the left lateral row is posterior to the peristome, about 8.5 microns from the body periphery. With the exception of the left median row, in which about four or five of the most posterior cirri are constantly missing, all the longitudinal rows extend almost to the posterior extremity of the body (Plate I, Fig. 1). Each row is set within a distinct groove in the pellicle, which is most clearly seen at the anterior end of the right lateral row. This groove extends over the rounded periphery to terminate on the margin of the dorsal surface. In individuals with few food vacuoles the longitudinal rows are equidistant from each other, but with increase in food contents, the median rows are slightly closer to each other than they are to the laterals.

The cirri in the longitudinal rows are more closely approximated to each other in some individuals than in others, and the number in each row in different individuals varies. Counts can be made on living specimens, but they can be easily and more carefully made on animals stained with China blue. However, in these preparations only in rare instances are all the four rows visible for their entire length, due to the contraction of the posterior extremity. (See summary below.)

On the ventral surface, posterior in position to the membranelle series, is a semicircular row consisting of a variable number of cirri. The position of the first cirrus at the right is constant-posterior to the first membranelle and opposite the first cirrus of the right median longitudinal row of cirri. Since the spaces between these cirri tend to be equal, the location of the last cirrus and the length of the row depends upon the number of cirri present in this row, which may be from 12 to 22 . This interesting departure from the ciliation ordinarily found in the Hypotrichida has also been described by Penard (1922) in Keronopsis helluo, and recently by Kahl (1932) in the two species of his new genus Paraholosticha. Accord ing to the former investigator, the transverse row extends only about half-way across the anterior end.

Additional frontal cirri are disposed in two short rows to the left of the left median longitudinal row of cirri, the spaces between the three rows being approximately equal to each other. Immediately to the left is the peristomal groove. The number of cirri is variable within each row. From two to six have been found in the right row and from one to five, in the left row ; the smallest number in any one individual is three, and the largest number, ten.

The variation in number of frontal cirri does not indicate that there are races or strains within the species having a constant pattern of frontal cirri. Pure line cultures have been grown and these show all the variations 
of the frontal cirri pattern found in a mixed culture. The two daughters of a single individual may vary in respect to the number of frontal cirri.

Isolated cirri originate at the right peristomal border posterior to the frontals. Their number varies from one to three.

The following is a summary of cirri counts made upon five living, unstained individuals, together with the number of membranelles and the length of the organism.

\begin{tabular}{|c|c|c|c|c|c|}
\hline $\begin{array}{c}\text { Body } \\
\text { Length. }\end{array}$ & Membr. & $\begin{array}{l}\text { Trans. } \\
\text { Row. }\end{array}$ & $\begin{array}{c}\text { Frontals } \\
\text { R., L. }\end{array}$ & Isol. & $\begin{array}{c}\text { Longit. Rows } \\
\text { R. to L. }\end{array}$ \\
\hline $100 \mu$ & 29 & 14 & $\begin{array}{ll}3 & 1\end{array}$ & 1 & $23,29,23,20$ \\
\hline 108 & 34 & 15 & 32 & 1 & $20,24,25,20$ \\
\hline 145 & 48 & 20 & 54 & 3 & $27,38,38,30$ \\
\hline 148 & 38 & 17 & 43 & 3 & $29,32,29,27$ \\
\hline 152 & 38 & 18 & 42 & 2 & $26,32,30,25$ \\
\hline
\end{tabular}

There is no appreciable difference in size among the ventral cirri. Except for the first two or three cirri at the anterior end of the right lateral and right median rows, and the isolated cirri, which appear to be slightly smaller, there is a remarkable uniformity in size of all the cirri of an individual. But the size of the cirri in different individuals varies, as is to be expected. The largest found measured fourteen microns in length.

Three longitudinal rows of cilia are found on the dorsal surface (Plate II, Fig. 4). The cilia are about three microns in length and are placed about five to six microns apart. Frequently two cilia originate at the same point. The dorsal cilia are not immotile (or very slightly movable) spines or bristles as found in Euplotes worcesteri Griffin (1910) and many other hypotrichs, but are definitely motile cilia, as can be readily demonstrated.

It has been generally believed that in the Hypotrichida motile organs are confined to the ventral surface (Calkins, 1926; Doflein-Reichenow, 1929 ; and others). S. sterkii then is unique in having cilia on the dorsal surface. On the other hand, careful and complete descriptions have not been made for many species on record, and therefore the presence of cilia may have been overlooked in some cases.

The peristome is a narrow longitudinal groove on the left ventral surface, slightly wider anteriorly than posteriorly. It originates between the left frontal row of cirri and the left end of the transverse row, and extends posteriorly for about two-fifths the length of the body. On the left the peristome is bordered by the membranelles, as already described. An undulating membrane is attached along the right border. The anterior end is often found directly opposite the third cirrus of the right frontal row, that is, when at least three are present in that row. Here the membrane is almost as wide as the peristome, but as it extends backward it 
gradually tapers to a point. Its posterior extremity extends into the cytopharynx.

The peristome opens into a funnel-shaped cytopharynx (Plate I, Fig. 1). One side of the "cone" is somewhat elongated anteriorly and ventrally it is flattened, forming the thin and transparent floor of the cytopharynx. The posterior portion (or stem of the funnel) extends diagonally across the body within the endoplasm, opening into the interior of the body above the right median row of cirri. The lumen of this posterior cytopharynx is ciliated, and in some specimens stained with hæmatoxylin, the wall appears to be lines with dense strands which retain the dye. Judging from the large size of starch grains often ingested by the organism, the cytopharynx is capable of considerable distension.

The entrance point of food probably accounts for the fact that some organisms were found which are thickest to the right of the main axis. A rapid intake of food, such as takes place after excystment or a period of semi-starvation, would cause the food vacuoles to accumulate there temporarily.

When the body is quite free from food particles, the cytoplasm is pale yellow in colour. The ectoplasm and endoplasm are not visibly differentiated from each other in the living organism. In stained specimens the thin pellicle is apparent, beneath which is a very narrow zone of clear ectoplasm. The remainder of the cytoplasm, or endoplasm, is finely alveolar, and within it lie the food vacuoles.

A conspicuous band of deeply staining granules, irregular in arrangement, sometimes occurs across the entire anterior extremity of the animal (Plate II, Fig. 5). They were seen also within the living organism as coarse refractile granules. The spherules described in connection with the membranelles are quite easily distinguished from them by their definite position and more intense staining property. The significance of the accumulation of these granules in some organisms has not been determined.

In the majority of individuals, four rounded macronuclei lie within the endoplasm. Two are anterior in position and two, posterior (Plate II, Fig. 6). Each has its accompanying micronucleus, which may lie within a distinct depression or near a flattened area of the macronucleus, or free in the endoplasm. The micronucleus is spherical in shape and during its interphase about 2.5 microns in diameter (fixed and stained organism). It is of the massive type.

It must be pointed out here that the free-swimming organisms present a varying picture with respect to nuclei. The process of fission is being studied and will be presented in a later paper. At the present time these studies indicate that each of the two new daughter individuals leaving the cyst wall usually contains four macronuclei and a varying number (2-6) of micronuclei, although frequently four of each type are present. This 
hypotrich, as stated earlier, divides only during an encysted state and more than one division does not occur. Conjugating individuals have never been encountered.

S. sterkii has one contractile vacuole, located in the endoplasm near the dorsal surface, behind and above the posterior end of the peristome. When the organism is under pressure, a more anterior contractile vacuole may appear in addition to the usual one. An illustration of the elasticity of the pellicle can be seen in connection with the pulsation of this organelle. When the animal is viewed in profile, the expanded vacuole raises the surface like a blister. With contraction the bulge disappears.

The anus is situated at the posterior end of the mid-line. On several occasions, preceding its opening, a vacuole appeared into which an excretory particle was received and then emitted to the exterior.

\section{Habitat and Behaviour.}

S. sterkii was collected from a puddle in Chelson Meadow, which, according to Sexton (1924, p. 342), is " a salt marsh near Plymouth reclaimed from the tidal part of the Plym a little more than a century ago, and protected from the tide by an embankment, the accumulation of drainage water being emptied through sluice-gates into the river only at rare intervals." Culture experiments show that the organism thrives equally well in tap water or in brackish water up to a concentration of one part sea-water to one part distilled water. This, of course, is not unusual considering the original habitat just described.

The organism is also otherwise well adapted to life in puddles of short duration. The newly excysted individuals may be exceedingly small, thin, and transparent, but the rate of feeding is so rapid that within a few hours, depending of course upon the amount of food present, their bodies become exceedingly plump. If the first reproductive cyst of an individual of this type is isolated, another division occurs within twelve hours, although the average fission rate seems to be one about every 24 hours. In other words, the organism is able to take advantage of a short favourable period. Further, binary fission takes place at all times within a cyst membrane, and, in many cases at least, the daughter organisms withstand drying.

Protective cysts can be induced at any time by evaporation of the medium, but they may form also when sufficient water is present. The causes of encystment have not been investigated, but even casual observation in connection with the culture of this ciliate convinces one that it is quite sensitive to its environment, and that this sensitivity is often expressed in terms of encystment or excystment.

S. sterkii tends to encyst in groups, as was found to be the case in 
Euplotes taylori (Garnjobst, 1928), so that the surface of the watchglass may be sprinkled with grape-like clusters. If complete evaporation of the medium takes place very quickly, or if the medium is removed at once following the formation of a cyst wall, the organism invariably dies. Whether accidental or not, the formation of clusters of cysts would then be of survival value, for cysts more central in position are protected from rapid dessication. This point has not been tested experimentally.

Cyst formation may be observed under the microscope in hanging drop preparations. Both protective and reproductive cysts may be formed if the organisms are chosen at random from a thriving culture. In either case the animal rotates in place until a rounded form is assumed and a cyst wall has been secreted, after which rotation continues for some time within

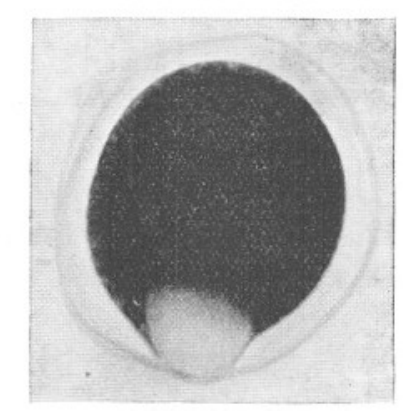

Text-Fig. 1.-Cyst of S. sterkii.

Photo-micrograph. Heidenhain's hæmatoxylin stain with very little destaining to show large vacuole. $\times 638$.

the wall. The reproductive cyst can be recognized while rotation is still in progress, for in these the macronuclei aggregate to form one large central mass, whereas in protective cysts they remain separated from each other. The macronuclear mass soon elongates and this indicates the position of the division plane, which is always at right angles to the elongation. Cytoplasmic division is preceded by the thinning of the macronucleus at its mid-region and final separation into two parts.

Sooner or later ciliary motion within both types of cysts discontinues. Now if the coverslip is placed within a moist chamber for several hours, or overnight, a large fluid vacuole appears, such as is shown in TextFigure 1. The space between the wall and the dedifferentiated organism is typical also of the living cyst.

Excystment may be induced by the addition of tap or distilled water, either before or after evaporation of the medium, at room temperature. Reproductive cysts which are formed without an accompanying evapora- 
tion of the surrounding medium, excyst spontaneously, that is, after the quiescent period ciliary motion again occurs, rotation commences, and in due time two new daughter individuals emerge through the cyst wall.

A detailed description of encystment and excystment will appear in a later paper.

\section{Systematic Position.}

In 1878 Sterki outlined a revision of the Oxytrichina instituting seven new genera, among which was Stylonethes which he characterized as follows :-

"Körper vorn verschmälert, hinten gerundet, stark gewölbt. Auf den vordern Hälfte des Stirnfeldes viele (15-20) zerstreute Wimpern, 2 Bauchwimperreihen, keine Afterwimpern. Die linke Randreihe beginnt auf dem Stirnfeld und überspringt das Peristom."

A single species, named $S$. tardus, was placed within the genus, but no description was given, the reason being that the author intended to give complete details in a later paper. This, so far as the writer has been able to learn, has never appeared.

Kent (1881, p. 782) stated that "so far as is at present possible to determine, this single type (Stylonethes) connects the two genera Holosticha and Uroleptus." Bütschli (1889), on the other hand, temporarily assigned $S$. tardus to the genus Uroleptus. In 1888, Gourret and Roeser described a new ciliate which they named Stylonethes fusiformis. The validity of this placement will be discussed below. Recently, Kahl (1932) described a new genus, Paraholosticha, including two species which bear a close resermblance to S. sterkii.

There are five distinct characters given by Sterki in his brief description of Stylonethes which are found also in the species herein described and in Kahl's $P$. herbicola and $P$. muscicola, namely, (1) four ventral, longitudinal, uninterrupted rows of cirri; (2) an anterior transverse row of cirri ; (3) differentiated frontal cirri ; (4) no anal cirri ; and (5) a rounded posterior extremity.

Sterki considered the transverse row as an anterior extension of the left marginal row of cirri which is interrupted by the peristome. Since it is not interrupted by a more or less undifferentiated space, as is the case in some species of the genus Oxytricha, but by the highly differentiated region, the peristome, it seems to the writer more convenient and correct to consider this row a separate one. It is true that Sterki did not designate precisely the location of this row, except to state that it begins on the frontal field. However, it is clear that in S. tardus there is present an anterior row of considerable length, otherwise Sterki would not have been able to differentiate these cirri from the scattered frontal cirri, which are quite numerous (15-20). Kahl (1932) in his description of S. tardus 
does not include the statement of Sterki, "Die linke Randreihe beginnt auf dem Stirnfeld und überspringt das Peristom."

Whether the anterior transverse row is of generic significance or not, the remaining four characters are sufficient to distinguish the species under consideration from other genera having few, uninterrupted, longitudinal rows of cirri on the ventral surface. These genera are (1) Uroleptopsis Kahl 1932; (2) Holosticha Wrzesniowski 1878, emend. Entz 1884 ; (3) Amphisia Sterki 1878, emend. Entz 1884 ; and (4) Uroleptus Ehrenberg 1831, emend. Stein 1859. The following summary illustrates this point :-

$\begin{array}{llll} & \text { Frontals. } & \text { Anals. } & \text { Post. Extremity. } \\ \text { Uroleptopsis } & \text { None } & \text { None } & \text { Rounded. } \\ \text { Holosticha } & \text { None } & \text { Present } & \text { Rounded. } \\ \text { Stylonethes } & \text { Present } & \text { None } & \text { Rounded. } \\ \text { Uroleptus } & \text { Present } & \text { Pres. in some } & \text { Tail } \\ \text { Amphisia } & \text { Present } & \text { Present } & \text { Rounded. }\end{array}$

Gourret and Roeser (1888) maintain that the characters of their S. fusiformis correspond in all respects to those laid down for the genus Stylonethes by Sterki, except that the marginal cirri are entirely lacking. This difference they did not consider sufficient to place the species elsewhere. If this were the only difference their stand might be justifiable, since in the closely related genera Holosticha and Amphisia, as emended by Entz (1884), there is a slight variation in number of ventral rows. However, it is difficult to understand the row of cirri along the right border of the peristome. These must have been considered the frontal cirri by the authors, otherwise the absence of frontals would certainly have been considered a second, if not an important generic difference. But, because of the similarity in position, it is also possible that they mistook an undulating membrane for a row of cirri ; or, they are cilia and not cirri. The description of the ciliation of the peristome is as follows: "Des deux côtés de la gouttière, le droit est un peu plus saillant; il porte des cirrhes plus vigoreux que ceux implantés à gauche " (p. 191). No further mention was made of this anterior row of cirri. Figure 13, Plate XIV is not adequate with respect to the ciliation of the peristome and is not convincing with respect to the presence of frontal cirri. For these reasons it seems to the writer that Gourret and Roeser's S. fusiformis cannot be placed with certainty within any genus. Kahl (1932) expressed doubt that it is a hypotrich.

S. sterkii and $P$. herbicola Kahl show a striking resemblance and it is not at all unlikely that they are one and the same species. If so, then S. sterkii should be called S. herbicola (Kahl). On the other hand, there are differences, according to determinations made from the figure and 
short description of $P$. herbicola (Kahl, 1932, Fig. 88). These are summarized below :-

\section{S. sterkii.}

1. Length, 94-160 $\mu$.

2. All 4 longitudinal rows of cirri, except left median row, extending to posterior extremity.

3. Anterior transverse row with 12-22 cirri.

4. 3-10 frontal cirri, in 2 short rows.

5. Cirri of ventral surface similar in size.

6. Dorsal cilia, in 3 longitudinal rows.

7. Isolated cirri near right peristomal border.

8. Intermembranelles present.

9. Dorsal contractile vacuole, above posterior end of peristome.

10. Macronuclei, 4 ; micronuclei, 4 .

\section{P. herbicola.}

1. $150-190 \mu$.

2. All 4 longitudinal rows of cirri extending to posterior extremity.

3. Anterior transverse row with $15-20$ cirri.

4. 16 frontal cirri, in 2 short rows.

5. Cirri of anterior transverse row and marginals larger.

6. Dorsal bristles or cilia (?) present.

7. No isolated cirri.

8. ?

9. Contractile vacuole some distance posterior to peristome.

10. Macronuclei, $2 ; 1$ micronucleus.

Some of these differences may be due to oversight on the part of Kahl. Yet this can hardly be said of his observations regarding the larger size of the cirri of the anterior transverse row, "Ganz nahe dem Vorderrand des Frontalfeldes ein Kranz zahlreicher verstärkter Cirren” (p. 545). Figure 88 shows larger cirri in the marginal rows, although no mention is made of it in the text. In Kahl's general description of the Hypotricha (1932, p. 533), the following statement is made of the marginal cirri, " . . . sie sind öfter etwas stärker als die eigentlichen Ventralcirren. . . ."

It seems impossible to the writer that anyone studying S. sterkii even for a short period would not have discovered its cysts. Kahl (1932) does not mention cysts. It is of course understood that a key is necessarily limited in matters of detail. However, in the separation of species if it should be found that in addition to minor differences, one species divides only within a cyst wall and the other does not, the character becomes significant as a specific difference.

The writer has already pointed out that in S. sterkii the free-swimming forms present a varying picture with respect to nuclei. According to Kahl, P. herbicola has two macronuclei with one micronucleus between. This condition is also found in some free-swimming forms of S. sterkii.

Kahl maintains that the most important difference between $P$. herbicola and $P$. muscicola is the presence in the former of two macronuclei and one micronucleus, and in the latter, of two to three micronuclei for each macronucleus. Figure 89 shows two macronuclei with reorganization bands, thus it does not represent the nuclear condition at the interphase. There are, however, other differences, (1) in length of organism ; (2) in the arrangement of the ventral, longitudinal rows ; (3) in length of peristomal 
field ; and (4) the presence of three cirri at the mid-line posterior in position to the frontal transverse row in $S$. muscicola.

It is of no consequence to the writer whether the form herein described is named S. sterkii or $S$. herbicola. A detailed description of $S$. herbicola would decide the matter. The key by Kahl (1932) has been available to the writer only very recently through the courtesy of Professor Kirby. Many changes have been made in the genera characterized by few uninterrupted rows of cirri on the ventral surface. The value of these changes can only be determined by those who have a thorough knowledge of the various types involved.

\section{Diagnoses.}

Credit is due Sterki for having recognized the distinctive characters of the genus which he created, but he also included those which are specific for S.tardus. Therefore, it seems desirable to restate the generic characters of Stylonethes briefly as follows :-

\section{Genus Stylonethes Sterki, 1878}

Paraholosticha Kahl, 1932.

Diagnosis: A hypotrich without neck or tail. Ventral surface with four uninterrupted longitudinal rows of cirri. Differentiated frontal cirri present, disposed in rows or scattered. No anal cirri.

\section{STYLONETHES STERKII sp. nov.}

Diagnosis: Body highly flexible, elongate-elliptical, anterior end with shallow excavation on left side, widest through middle, width about $\frac{2}{5}$ to $\frac{1}{2}$ of length. Anterior extremity having ventrally, transparent projecting lip; dorsally, membranelles extending sinistrally from termination of right median ventral row of cirri following peristomal border. Dorsal surface elevated, thickest centrally, periphery rounded; with 3 longitudinal rows of cilia. Ventral surface slightly concave with 4 (2 median and 2 lateral) uninterrupted rows of closely-set cirri, median ventrals traversing frontal field. Twelve to 22 cirri form a ventral transverse row immediately posterior to membranelle series. Differentiated frontal cirri in 2 rows between the left median ventral row of cirri and peristomal field ; number of cirri in these rows variable-left, 1-5, right, 2-6. One to 3 isolated cirri posterior to frontal cirri and near right peristomal border. Peristomal field narrow, length about two-fifths of body; undulating membrane on right border. Cytopharynx directed obliquely, opening centrally above right row of median ventral row of cirri; ciliated. A dorsal contractile vacuole above posterior extremity of peristomal field. Anal opening at mid-line of posterior extremity. Four macronuclei, two 
anterior and two posterior. Micronuclei 4, position variable. Binary fission in encysted state only. Length $94-160 \mu$; width $38-70 \mu$. Habitat, fresh water or brackish. Locality, Chelson Meadow, Plymouth, England.

\section{STYLONETHES TARDUS Sterki 1878.}

Diagnosis: Differentiated frontal cirri scattered, 15-20 in number. Two median ventral rows of cirri probably not traversing frontal field. Species without figures and dimensions.

\section{REFERENCES.}

Bresslau, E. 1921. Die Gelatinierbarkeit des Protoplasmas als Grundlage eine Verfahrens zur schnellaufertigung gefärbter Dauerprapärate von Infusorien. Arch. Protistenk, Vol. 43, pp. 467-481.

Bütschli, O. 1889. Bronn's Klassen und Ordnungen des Thierreichs. Protozoa. Vol. I, Abt. 3.

Calkins, G. N. 1926. Biology of the Protozoa. Lea and Febiger: Philadelphia.

Doflein-Reichenow. 1929. Lehrbuch der Protozoenkunde. Fischer: Jena.

ENTz, G. 1884. Über die Infusorien des Golfes von Neapel. Mitt. zool. Sta. Neapel, Vol. 5, pp. 289-444.

Garnjobst, Laura. 1928. Induced encystment and excystment in Euplotes taylori sp. nov. Physiol. Zoöl., Vol. I, pp. 561-575.

Gelei, J. v. 1929. Ein neuer Typ der hypotrichen Infusorien aus der Umgebung von Szged, Spirofilum tisiœ n. sp., n. gen., n. fam. Arch. Protistenk, Vol. 65, pp. 165-182.

Gourret, P., and Roeser, P. 1888. Contribution à l'étude des Protozoaires de la Corse. Arch. Biol., Vol. 8, pp. 139-204.

Griffin, L. E. 1910. Euplotes worcesteri sp. nov. I. Structure. Philipp. Journ. Sci., Vol. 5, pp. 291-312.

Kahl, A. 1932. Die Tierwelt Deutschlands. I. Wimpertiere oder Ciliata (Infusoria). 3. Spirotricha. Fischer: Jena.

Kent, W. S. 1881. A manual of the Infusoria. Vols. II and III. Bogue, London.

Penard, E. 1922. Étude sur les Infusoires de d'eau douce. Georg et Cie, Genève.

Rossolimo, L. 1929. Ueber Spirofilum tisice Gelei und Hypotrichidium conicum Ilowaisky. Zool. Anz., Vol. 86, pp. 69-74. 
Sexton, E. W. 1924. The moulting and growth-stages of Gammarus, with descriptions of the normals and inter-sexes of $G$. chevreuxi. Journ. Mar. Biol. Assoc., N.S., Vol. XIII, pp. 340-401.

Stein, F. 1859. Der Organismus der Infusionsthiere. Abt. I. Hypotricha. Engelmann, Leipzig.

Sterki, V. 1878. Beitrag zur Morphologie der Oxytrichen. Z. wiss. Zool., Vol. 31, pp. 29-59.

TAYLOR, C. V. 1929. Experimental evidence of the function of the fibrillar system in certain Protozoa. Amer. Nat., Vol. 63, pp. 328345 .

Wallengren, H. 1900. Studier öfver ciliata Infusorier. IV. Lunds Univ. Arsskr., Vol. 36, pp. 1-54.

Wrzesniowski, August. 1877. Beiträge zur Naturgeschichte der Infusorien. Z. wiss. Zool., Vol. 29, pp. 267-323. 